\title{
The Productivity Growth-Technology-Entrepreneurship Nexus: Implications for Pakistan
}

\section{Irfan ul Haque *}

\begin{abstract}
Labor productivity growth has received scant attention in Pakistan even though it is the foundation of rising living standards and a country's ability to compete in the world market. Productivity rises when producers invest and introduce new technologies to reduce production costs and improve the quality and range of goods produced. Competition among producers entails a constant search for areas of improvement, tapping new technologies and finding innovative ways to produce and deliver the output to consumers. This is entrepreneurship. The first part of the paper discusses productivity growth and its drivers. The second part explains the critical importance of technological progress and innovation in economic growth and the catch-up process. Entrepreneurship and how it might be stimulated in Pakistan is discussed next. The paper concludes with a few ideas on how science and technology might be promoted in Pakistan.
\end{abstract}

Keywords: Labor, productivity, entrepreneurship, Pakistan.

JEL classification: E24, O14.

\section{Introduction}

Productivity growth is the basis of rising living standards and a country's ability to compete in the world market. Productivity improves when producers seek ways to lower costs and improve the quality and range of goods and services produced. This entails tapping new technologies and finding innovative ways to produce and deliver products to the consumer - a task typically performed by entrepreneurs. They innovate, adopt and adapt new technologies in production and distribution and, in the process, raise productivity. However, in traditional neoclassical economics, productivity growth is not a dominant concern but rather incidental to producers' efforts to maximize profits. This paper attempts to elucidate the nexus of productivity growth, technological progress and entrepreneurship and examine its implications for Pakistan.

\footnotetext{
* The author is an unaffiliated researcher, who has worked for the World Bank, South Centre and UNCTAD.
} 


\section{Productivity Growth}

A country's per capita income depends directly on labor productivity, as can be seen from the following two relationships:

Per capita income $(Y / P)=$ labor productivity $(Y / E) \times$ employment rate $(E / N) \times$ labor force participation rate $(N / P)$

where $\mathrm{Y}$ is national income, $\mathrm{P}$ is population, $\mathrm{E}$ is employment and $\mathrm{N}$ is the size of the labor force. Expressing equation (1) in terms of growth rates:

Growth of per capita income $=$ growth of labor productivity + proportionate change in the employment rate + proportionate change in the labor participation rate

The first relationship is simply an identity: per capita income is the product of labor productivity, the proportion of labor force employed and the proportion of active labor force in the population. The second relationship, derived from the first, states that the growth of per capita income is the sum of the growth in labor productivity and proportionate changes in the employment rate and labor force participation rate. In other words, per capita income can rise on account of an increase in any of the three factors on the right-hand side, i.e., labor productivity, the employment rate and labor force participation rate. Over the longer term, however, since unemployment and labor force participation rates change only within fairly narrow limits, the growth of per capita income depends primarily on growth in labor productivity.

A country's terms of trade also affect national real income. An improvement in the terms of trade is analogous to an increase in productivity because the country can obtain more in imports for a given volume of exports, i.e., the domestic resource cost. How the terms of trade move over time is not usually within a country's control and depends largely on exogenous episodes such as war, crop failures, new resource discoveries or mining disasters. Countries might want to move the terms of trade in their favor but they have few means available to make this happen on a sustained basis.

The overall growth of labor productivity is affected by an economy's sectoral orientation (some sectors tend to have higher labor productivity) and the growth in productivity of individual sectors, that is: 
Overall productivity growth $=\Sigma$ (individual sectors' productivity growth $\mathrm{x}$ the sector's weight in GDP)

In other words, overall productivity rises both because individual sectors experience technological improvements and because the economy's structure moves toward more sophisticated, higherproductivity sectors. This simple and rather obvious proposition is at the heart of economic progress: as economies evolve, higher-productivity or higher value-added sectors gain in salience. However, the above relationship also shows that, because of their weight in the economy, traditional sectors remain dominant in the economy's overall performance in the earlier phases of development. How long this lasts depends on the pace of economic restructuring.

Another implication of Equation 3 is that, from the viewpoint of longer-term economic growth and development, the choice of industry does matter. Some industries simply have far greater potential for productivity growth, at least during certain phases of their evolution. This has been described graphically as a country having to choose between producing potato chips and microchips.

Whether productivity growth materializes through sectoral shifts or in-sector improvements, science and technology (S\&T) capabilities are at the core of the change. Higher-productivity sectors generally, but not always, tend also to be technologically more sophisticated - aircraft manufacturing is more technologically challenging than garment production - while sectoral productivity growth materializes as technologically more advanced production processes come to be used. Occasionally, this can be phenomenal, as was observed during the revolutionary improvements in agricultural practices of the past 50 years.

There are three ways that productivity in a particular sector might rise. First, at any given time, individual industrial plants may operate at different levels of efficiency on account of organizational or management differences (the so-called " $X$-inefficiencies"). As lagging producers emulate the available best practice, overall sectoral efficiency will rise. Second, at any given time, different plants may employ machinery of different vintages since producers install and scrap equipment at different rates. Again, as more producers employ newer equipment, overall productivity will rise. Finally, there are the developments in the "state of the art": the introduction of new products and processes, typically resulting from research and development (R\&D). It is only in this instance that new 
knowledge is being generated; the first two cases represent the result of knowledge diffusion. In the face of such developments, the "best practice" is not a fixed point, but rather a moving target and technological catch up is a challenge and a continuing process.

Thus, whether it is sectoral shifts or in-sector growth, the long-term growth in labor productivity is driven by technological progress. ${ }^{1}$ There is, however, a real conflict here. While countries seek to realize steady improvements in living standards, which involves rising productivity, profit maximization on the part of producers may not necessarily be consistent with that goal. Producers want to control production costs; how that is achieved is generally of little concern to them. In the process, they often take shortcuts that hurt the longer-term economic growth. This issue is discussed further below.

\section{Pakistan's Productivity Performance}

Labor productivity performance receives scant attention in Pakistan, which is evident from the paucity of data on this critical metric. The last released census of manufacturing was conducted in 2006 and the data on value added in key industries for recent years are more or less just best guesses. By contrast, in advanced countries and particularly in East Asia, labor productivity is watched with great interest as it is a key indicator of competitiveness and overall economic performance. Indeed, Japan, which demonstrated that it was possible to catch up with the more advanced economies, established an organization specifically tasked to gather productivity data for Japan as well as its competitors. The Asian Productivity Organization, based in Tokyo, now covers the entire region and aims to support "member economies in acquiring practical, state-ofthe-art tools and knowledge to foster productivity at industry and enterprise levels" (2015, p. ix).

The organization's data show that Pakistan's overall productivity registered the lowest growth of all Asian economies during 2000-11 - just a little over 1 percent a year - in contrast to China's 10 percent and India's 8

1 The standard neoclassical model of economic growth defines technological progress as total factor productivity (TFP), which is meant to capture the productive efficiency of all factors of production. However, TFP is typically measured by making stringent assumptions regarding the form and properties of the production function, itself an intrinsically flawed concept. TFP has been called "a measure of our ignorance" and estimates are entirely unreliable. The growth in labor productivity, which is conceptually more robust, can be taken to reflect technological progress since even when it results from more capital being used, it signifies technological progress (Salter, 1966; Dosi, Pavitt \& Soete, 1990; Haque et al., 1995). 
percent. With respect to productivity in manufacturing, Pakistan's growth at 2.3 percent a year, while not the lowest, makes it among the poorest Asian performers. The country data show that Pakistan's productivity level in manufacturing was half that of Indonesia and a quarter that of Malaysia in the early 1990s, but this gap widened considerably over time, especially with respect to Malaysia. In 2007, Malaysia was more than ten times as productive and Indonesia three times as productive as Pakistan (Haque, 2014). In other words, far from catching up, Pakistan fell far behind the other two Asian economies. The country's export failure and lack of competitiveness is thus largely attributable to its dismal productivity growth, especially in manufacturing, although a common perception is that the lack of diversification and concentration on low-technology industries is the principal cause (for a detailed discussion, see Haque, 2014).

While a number of factors could be held responsible for low productivity in Pakistan's case - power availability, other infrastructure weaknesses and, not least, the security situation - extremely low investment in physical and human capital must be considered the nub of the problem. With an investment rate of barely 15 percent of GDP, Pakistan ranks among the world's lowest investors. This means that Pakistan's capital stock is, on the whole, much older than its competitors', over time becoming increasingly so. Obviously, where investment rates have been high - as, for example, in China or India - the existing capital stocks are much younger and more efficient (Haque, 2014). In short, Pakistan needs targeted policies not only to foster adoption of technological improvements at the firm level, but also to achieve a higher investment rate at the macroeconomic level. There is urgency to this because the economy is currently operating far below its potential and continues to fall further behind other developing economies.

\section{Technological Progress and Innovation}

Producers' ability to introduce improvements in products and processes depends on the stock of knowledge and information they are able to access and use. However, a precondition for innovation is that producers are seeking improvement - actively looking for ways to improve the quality and range of products they produce - and do so while reducing production costs. Such producers are the classic Schumpeterian entrepreneurs.

In mainstream economics, technological progress has not gone beyond the status of an add-on. In the earlier neoclassical growth models pioneered by Robert Solow and others, technological progress was 
introduced as a scalar, a multiplicand that uniformly shifted upwards the constant-returns-to-scale production function. Thus, in effect, what was described as technological progress was just the unexplained part of the regression estimates of the production function.

Subsequently, the theoretical discussion progressed to include "learning by doing" - a concept Arrow introduced in 1962. This was an attempt to explain why producers fail to produce at the optimal level even when facing identical production conditions. The explanation for the observed variance in productive efficiency across producers was that it takes time to acquire the necessary experience and expertise to operate new equipment. While this idea was innovative at the time, it too was fundamentally static and explained a rather narrow issue.

The endogenous economic growth models of the 1980s led by Romer took the discussion of technological progress a little further and sought to explain why productivity rises, but provided little guidance to investors or policymakers. They failed to explain the historically observed general widening of income disparity across countries or the phenomenal success of some countries in catching up with the more advanced economies. The models were mathematically challenging and of little practical value and gradually faded away from the economic discourse.

The fact is that technological progress is difficult to "model" in the sense of generalizable and predictable behavior. Perhaps the foremost reason is that knowledge does not transfer easily and the sharers of knowledge often have differing views as to its economic significance. Thus, people tend to respond differently to a given piece of information and producers may have different notions as to what works and what may not. For example, among car manufacturers, some producers favor hybrids over fully electric cars and some continue with the traditional petrol engines. In short, producers tend to place different bets in the choice of technology.

Closely related is the fact that technological blueprints are just guides and require adaptation to local circumstances before being implemented. Thus, even when production techniques or designs can be borrowed, a great deal of plant-level innovation and ingenuity is involved in making them work at a new plant site. The transfer of knowledge across countries is particularly difficult because of differences in culture, legal or regulatory requirements and the natural environment. All these considerations present enormous practical and theoretical difficulties in incorporating knowledge and technological progress within traditional 
economic models. Where economists have tried, they have ended up drawing fairly bizarre conclusions. ${ }^{2}$

It is often difficult to distinguish between innovation and imitation, as both require accumulation of knowledge. The difference is that, in one case, the knowledge frontier is being extended, and in the other, the individual producer is striving to move towards that frontier. In both cases, however, learning has to take place and ideas require adaptation and modification to local reality. Moreover, while technological progress is crucial to productivity improvements and economic growth, it can also go in the opposite direction. An environment of rapid growth and global competition itself can and often does stimulate the search for new and improved methods of production and encourage scientific research. In this virtuous circle, economic growth and technological progress feed on each other. As Nelson (1981) notes:

Just as a high rate of capital formation and a welleducated workforce stimulate technological advance, so technological advance stimulates a high rate of capital formation and motivates young people to acquire formal education (p. 1055).

Crucial to the learning is a certain level of understanding of science and mathematics. Scientific knowledge that enhances our understanding of the workings of the physical environment is the basis for technological progress. As Dr Abdus Salam observes:

Three centuries ago, around the year 1660, two of the greatest monuments of modern history were erected, one in the West and one in the East: St Paul's Cathedral in London and the Taj Mahal in Agra. Between them, the two symbolize... the comparative level of architectural technology, the comparative level of craftsmanship and the comparative level of affluence and sophistication the two cultures had attained at that epoch of history. But at about the same time there was also created - and this time only in the West - a third monument, a monument still greater

\footnotetext{
${ }^{2}$ An egregious case is that of Grossman and Helpman (1991), who view R\&D as an economic activity subject to the law of comparative advantage. They argue that it would be a waste of world resources if countries seeking to catch up in technology were to subsidize $R \& D$ as they do not have a comparative advantage in undertaking R\&D: "The inefficiency in world research implies a loss of world output, and in general every country finds itself sharing in the loss" (p. 341).
} 
in its eventual import for humanity. This was Newton's Principia, published in 1687 (cited in Lai, 1987).

Apart from material progress, scientific and technological developments contribute to the quality of life, reducing morbidity and extending life expectancy. Even more significant is that science promotes the advancement of knowledge by fostering intellectual curiosity, sharpening observation of natural and social phenomena and promoting a culture of problem solving. All these factors contributed to the rapid advancement of the US and European economies during the last two centuries - a lead that remains more or less intact.

However, the science-technology, technology-economic progress links are far from unambiguous. There is, for example, no certainty that enhanced scientific education and research will readily yield commercially viable technologies (as, for example, was the case with the scientific achievements of the former Soviet Union) or that technological advances will immediately lead to more rapid economic growth (the revolutionary strides that information technology has taken in recent years have yet to translate into significant productivity growth). However, science also progresses through technological innovations: for example, the increasing sophistication of measuring instruments was an important contributor to the scientific advance. Similarly, the capacity of computers to handle increasingly complex mathematical problems as well as the Internet have greatly facilitated research.

Nevertheless, there is strong evidence of a close relationship between investment in S\&T and economic performance. Several studies show R\&D expenditures and economic growth to be closely linked (see Dosi et al., 1990; Fagerberg, 1988). Fagerberg finds that "to catch up with the developed countries... semi-industrialized countries cannot rely only on a combination of technology import and investments, but have to increase their national technology activities as well" (1988, p. 451).

Investment in education and skills is widely recognized as crucial to countries' ability to catch up with the more advanced economies. The East Asian economies provide a clear example of that. A number of studies show that countries that invested more in human capital (measured in terms of school enrolment rates), other things being equal, tended to grow faster than those that did not (see, for example, Barro, 1991; Baumol, Blackman \& Wolff, 1989; World Bank, 1993). There is some evidence that the quality of education in science and mathematics is also a significant 
factor in explaining a country's economic performance. The high economic performance of Singapore, Korea and Japan during 1970-90 was seen to be associated with the top high school scores in science and mathematics.

In all these respects, Pakistan is a laggard. It ranks low in terms of general education, S\&T capabilities and R\&D by industry. According to the National Science, Technology and Innovation Policy (NSTIP) 2012, Pakistan has only 162 researchers per million of population, compared to 2,000-5,000 in advanced countries. Similarly, "technician-level manpower" is 64 per million, compared to 1,500-2,000 in advanced countries (Pakistan, Ministry of Science and Technology, 2012, p. 12). The policy document also notes: "As there was no real demand from industry, the R\&D system of the country is oriented towards the supply side. R\&D activity in the industrial sector itself is assumed to be negligible. This is in contrast to the industrialized countries where the industrial sector is a major contributor to the overall R\&D effort of the country" (p.x).

There are several reasons for the current state of affairs. The first and foremost is that S\&T in Pakistan, as in most other developing countries, has been largely the state's responsibility in the face of severely constrained administrative and financial capacity to carry out the task. At the same time, S\&T has not been recognized as a central issue in the discussion and formulation of Pakistan's development plans and economic policy. The Planning Commission's Framework for Economic Growth issued in 2011 underscored the country's poor productivity performance, but saw the remedy in improving the quality of governance, market liberalization, deregulation and generally letting the government move out of the way of private enterprise. The fact is that Pakistan's business community has shown little Schumpeterian entrepreneurship and appreciation of the importance of S\&T in economic advancement and international competitiveness. The next section addresses this issue.

\section{Entrepreneurship}

A country's economic prowess and international competitiveness depend on how its business firms perform in the world market. Their ability to generate and manage technological change - bringing to the market new products, lowering production costs - drives the growth in sales and profits. An economy dominated by technologically dynamic firms can be expected to prosper and grow faster. The postwar catch-up of the Japanese economy with the US and other industrial countries was nothing but a reflection of the stellar performance of its firms. Other major 
emerging market economies too - China, India, Korea, Taiwan - are known for their world-leading firms. On the other hand, Pakistan, a country of 200 million with a per capita income comparable to India's, cannot boast of a single firm being a significant player in the world market.

There is much to lament on Pakistan's industrial development performance. Industry is concentrated in textiles and very little diversification toward higher-productivity sectors has occurred over time. Productivity growth has been modest and Pakistani firms' performance in the world market has, with a few exceptions, lagged far behind that of their competitors. While other economies in Asia Bangladesh, China, India, Indonesia - have taken strides in world exports, Pakistan's export-to-GDP ratio has declined over the past three decades and is now around 10 percent.

As to the causes of this sad economic record, researchers' default position has been to blame the country's over-protective regime, overregulation and over-interfering government, which together are believed to have stifled entrepreneurship. According to Haque (2007):

We see that entrepreneurship in Pakistan is seriously impaired by government policy, legislation and regulation. The government has continuously been of the opinion that investment especially at the large industrial level is entrepreneurship. As a result, it has been unable to promote genuine entrepreneurship and promoted cartelization and rent-seeking instead (p.9).

This diagnosis leads to rather obvious policy prescriptions: to undo the prevailing policy and governance regime by liberalizing trade, deregulating and letting the government generally move out of the private sector's way. Under this policy environment, rent-seeking firms are expected to become efficiency seekers and profit maximizers, enabling the country to join the ranks of other star performers. This reasoning, however, is seriously flawed and has been questioned elsewhere (see, for instance, Haque, 2014, 2015). It is enough here to note that, while Pakistan is far from being a paragon of economic liberalism, it compares favorably with other Asian countries that performed well in recent times.

Over the years, the World Bank's doing-business indices (notwithstanding their deficiencies) have placed Pakistan ahead of China or India in several respects (Haque, 2014). According to Transparency 
International's global corruption barometer for 2013, Pakistan ranks 34 while India ranks 54.3 Pakistan has also taken steps toward market liberalization and deregulation over the past two decades. Protection has been lowered considerably and several state-owned companies privatized, the capital account is now virtually free and measures have been introduced to create a more business-friendly environment. Thus far, the fruits of these measures are hard to perceive. Critics argue that more needs to be done, but from the results so far, it appears that, not more, but something different, might be required.

A firm's performance depends on the drive and entrepreneurship of its managers and owners, whose decisions on investment, worker training, marketing and R\&D reflect its responsiveness to technological challenges. Ethnicity is sometimes seen to be associated with entrepreneurship, but it is ultimately financial institutions and economic policy that influence investors' attitude to risk and innovation and whether they base their decisions on longer-term considerations or opportunities for quick payoffs.

There has been, over the years, a keen debate on the relative merits of the so-called Anglo-Saxon model, driven by stock market financing and shareholder value, against the traditional Continental or Japanese model, where banks play the dominant role in firm financing. Search for profit is central to the market economy, but what distinguishes the leadership of a successful firm in the long term is how that goal is pursued. Financial manipulation and other short-term measures of cost cutting, such as neglecting quality and worker training, may improve the firm's "bottomline" but its survival ultimately depends on investments to improve its products, services and production processes. The question is whether it is possible to devise government policies, regulations and institutions that induce firms to invest in areas that are conducive to the country's longerterm growth and to seek profit opportunities in productive rather than unproductive rent-seeking. This issue is taken up in the concluding section.

\section{Promoting S\&T in Pakistan}

For Pakistan to emerge as a dynamic and internationally competitive economy, considerable investment and a fundamental change in priorities is needed to build up local capabilities to generate and manage technological change. At present, these capabilities are totally inadequate

\footnotetext{
${ }^{3}$ http://www.bbc.co.uk/news/business-23231318
} 
to meet the challenges of the global economy and the 21st century. The pace of technological change in Pakistan compares very poorly with the performance of some of its Asian competitors. This is the principal explanation for Pakistan's slow economic growth and faltering performance in the world market.

Promoting S\&T requires, on the one side, business firms that are entrepreneurial in their actions and approach to investment decisions and, on the other, the available knowledge and information. To carry out the entrepreneurial firms' plans and investments, the availability of suitably skilled workers is a sine qua non. The goal of national development must be to promote technologically dynamic firms. Just as sports champions are created rather than selected, the careful nurturing of firms is key to their success in the world market. As a laggard in industrial development, Pakistan suffers from a host of disadvantages that call for government help and support.

The NSTIP 2012 is an ambitious, visionary document containing many useful ideas and proposals for promoting S\&T in Pakistan. It suggests a number of institutional reforms, notably the re-composition of the National Commission for Science and Technology and its executive committee and the establishment of a high-level Pakistan Council for Science and Technology. The NSTIP also emphasizes the need to expand and improve the country's human resource base by improving syllabi and enhancing teachers' skills. Among its "thrust areas", the policy document accords highest priority to metrology, standards, testing and quality control, in which Pakistan's current status is fairly dismal. Environment, health and pharmaceuticals and several other areas are also underscored.

Sadly, however, four years have elapsed with little progress on any of these proposals. It is not even clear whether the government any longer accepts the NSTIP as a basic policy document. Nevertheless, the policy statement provides a good basis to start rethinking the national approach to science, technology and innovation. The foremost step in this process would be to foster much closer coordination of economic policy and focus on balancing the sources of supply (scientists and engineers) and demand for S\&T capabilities (mainly the business sector). Specifically, the government has a critical role in:

- Promoting a commitment to national development among firm managers and owners 
- Promoting a culture of technological improvement and upgrading within business firms

- Fostering a long-term strategic perspective of catching up with world leaders in the relevant industries

- Establishing closer employer-worker relationships to achieve higher productivity growth and improvements in product quality

- Ensuring that new firms can join the group of high performers while facilitating the exit of those that fail.

The National Commission for Science and Technology could provide the institutional setting for improved contact and interaction among the business, education and industry sectors to ensure demanddriven technology development and absorption. It could do so by making known to industry - through seminars, reports and other means of publicity - the work program and output of local research institutes. It could also organize seminars and conferences at Pakistani universities, colleges or even schools to expose them to the needs of business and industry. Equally important would be assistance and advice on how local R\&D institutions could market their services to industry. An important resource to tap is the overseas Pakistani community of engineers, scientists and technology experts who are eager to serve Pakistan on an ad hoc basis.

The traditional approach to building up technological and scientific capacity, which relies on spreading education and developing $R \& D$ institutions, will yield results too slowly in a rapidly changing world. Pakistan, in the meantime, will have fallen further behind the more advanced developing countries. If it is to catch up with them, it will need to take shortcuts to developing local S\&T capabilities and laying the foundations for a robust national system of innovation, enabling the country to leapfrog to the technological demands of the 21st century.

Pakistan has not only fewer scientists and engineers per capita than the rapidly growing economies, but the available S\&T capabilities are also generally inferior and poorly used. A major reason for this is that neither the government nor the business community have been able to create a robust R\&D infrastructure, notwithstanding several bright spots in research and innovative activity that call for scaling up and replication countrywide.

Since Pakistan's financial and administrative resources for promoting S\&T can be expected to remain severely constrained, it will 
need to prioritize the development of S\&T capabilities. To this end, the government has four areas of action at its disposal:

- Macroeconomic policy. Investment decisions are susceptible to the country's macroeconomic policy. Traditional stabilization measures are usually targeted at reducing demand, hurting economic growth, which in many cases becomes an endless process, as we have witnessed in Pakistan. The result is that, despite attempts at stability, inflation persists while economic growth is choked. However, it is often possible to adopt what are called "heterodox" policies that seek to ensure adequate public and private sector investment while achieving economic stability with economic expansion. The scope of such measures in Pakistan is discussed in Haque and Amjad (2012).

- Financial system. How investments are financed can be crucial both to their orientation and their pace. In the earlier phase of economic development, Pakistan had institutions that financed private investment. Under the sweep of neoliberalism, these development finance agencies (PIDC, PICIC) were allowed to wither away, even as private bank financing failed to fill the gap. Monetary policy in Pakistan is concerned only with the height of interest rates, but not the actual availability of financing for new investment ventures.

- Industrial policy and incentives regime. The successful industrialization of East Asia has demonstrated that industrial policy can be a very effective instrument for economic change. While times have changed and Pakistan's circumstances are different, there is much that the country can learn from the East Asian experience (Haque, 2014). Two things in particular are important. First, industrial policy is needed to create a common vision or direction for industrialization among firms. Second, while incentives are useful to help move investment decisions in the chosen direction, the government needs to devise and implement a system of rewards and penalties to ensure that the established economic goals and targets are realized.

- Regulatory environment for domestic competition. An important aspect of the East Asian experience, notably that of Japan, is the role played by domestic competition as the force behind national firms becoming strong competitors internationally. While the disciplining force of international competition is stressed in the development literature, it is the domestic competitive environment that is more relevant to industry. For one thing, a major segment of industry supplies primarily the domestic market. For another, the ease of entry and exit of firms in 
the domestic market may offset the harm done by protection. Indeed, the rate of entry and exit of firms (and sometimes also entry plus exit) is a practical and useful measure of entrepreneurship.

Finally, there is the question of education in science and engineering. No country has developed without having an adequate supply of high-level scientists and engineers. As Dr Abdus Salam observed: "It is just impossible to talk only of technology transfer. One should talk of science transfer first and technology transfer later ... Unless you are very good at science you will never be good at technology" (cited in Pakistan, Ministry of Science and Technology, 2012).

There is, therefore, a need to develop ideas on how educational institutions might respond to the emerging requirement for scientists and engineers. A critical issue that many other countries (including advanced countries) also face is what can be done to make the study of sciences, engineering and mathematics attractive fields at the school and university level. Paradoxically, many developing countries, including Pakistan, suffer from the problem of unemployed and unemployable scientists and engineers. This may be the result of poor quality or an unsuitable mix of available skills, which again calls for improving the quality of education as well as building closer relationships between businesses and the institutions engaged in science and engineering education. 


\section{References}

Asian Productivity Organization. (2015). APO productivity databook 2015. Tokyo: Keio University Press.

Barro, R. J. (1991). Economic growth in a cross-section of countries. Quarterly Journal of Economics, 106(2), 407-443.

Baumol, W. J., Blackman, S. A., \& Wolff, E. N. (1989). Productivity and American leadership: The long view. Cambridge, MA: MIT Press.

Dosi, G., Pavitt, K., \& Soete, L. (1990). The economics of technical change and international trade. London: Harvester Wheatsheaf.

Fagerberg, J. (1988). Why growth rates differ. In G. Dosi, C. Freeman, R. Nelson, G. Silverberg \& L. Soete (Eds.), Technical change and economic theory (chap. 20). London and New York: Frances Pinter.

Grossman, G. M., \& Helpman, E. (1991). Innovation and growth in the global economy. Cambridge, MA: MIT Press.

Haque, I. (2014). Toward a competitive Pakistan: The role of industrial policy [Special edition]. Lahore Journal of Economics, 19, 61-90.

Haque, I. (2015). Theory at odds with best practice: The travails of industrial policy [Special edition]. Lahore Journal of Economics, 20, 87-106.

Haque, I., \& Amjad, S. (2012). Toward a heterodox approach: Reconciling stabilization and economic growth in Pakistan [Special edition]. Lahore Journal of Economics, 17, 1-32.

Haque, I., Bell, M., Dahlman, C., Lall, S., \& Pavitt, K. (Eds.). (1995). Trade, technology and international competitiveness (EDI Development Studies). Washington, DC: World Bank.

Haque, N. (2007). Entrepreneurship in Pakistan (Working Paper No. 29). Islamabad: Pakistan Institute of Development Economics.

Lai, C. H. (Ed.). (1987). Ideals and realities: Selected essays of Abdus Salam (2nd ed.). Singapore: World Scientific Publishing Co. 
Nelson, R. R. (1981). Research on productivity growth and productivity differences: Dead ends and new departures. Journal of Economic Literature, 19(3), 1029-1064.

Pakistan, Ministry of Science and Technology. (2012). National Science, Technology and Innovation Policy 2012. Islamabad: Author.

Salter, W. E. G. (1966). Productivity and technical change (2nd ed.). Cambridge: Cambridge University Press.

World Bank. (1993). The East Asian miracle: Economic growth and public policy. New York, NY: Oxford University Press. 